\title{
Management of Widespread Skin Thickening in Diffuse Systemic Sclerosis
}

\author{
Suzanne Kafaja, $M D^{*}$ \\ Philip Clements, MD, MPH
}

\author{
Address \\ "David Geffen School of Medicine at UCLA, Division of Rheumatology, 1000 \\ Veteran Ave, Rm 32-59, Los Angeles, CA, USA \\ Email: skafaja@mednet.ucla.edu
}

Published online: 11 March 2016

(C) Springer International Publishing AG 2016

This article is part of the Topical Collection on Scleroderma

Keywords Systemic sclerosis - Diffuse cutaneous scleroderma - Mycophenolate · Cyclophosphamide - Methotrexate • Tocilizumab · Autologous stem cell transplantation · Rituximab · Intravenous immunoglobulin

\section{Opinion statement}

Skin thickening is one of the early organ manifestations of systemic sclerosis (SSc) and has a great impact on quality of life (QOL) as well as overall daily living in patients with SSc. The dynamic changes that occur as the disease progresses and as other organs become further involved present the treating physician with therapeutic challenges. Hence, when considering drug therapy for skin disease, the treating physician should consider a number of factors including disease duration, the rate of skin thickening, the extent of disease progression, organ involvements, and patient-related outcome measures, all of which impact the type of treatments considered. For early diffuse skin disease, we prefer the use of methotrexate (MTX). And when there is evidence of lung involvement or tendon friction rubs (given its association with ILD development), we tend to shift to the use of mycophenolate or cyclophosphamide because these agents have been shown efficacious for the specific indication of lung disease in SSc. We have managed joint disease, on the other hand when present, with MTX or other DMARDs, as well as the use of biologics when there is evidence of inflammatory polyarthritis or rheumatoid arthritis overlap. While the treatment of myositis in the setting of SSc can present a therapeutic dilemma, reluctantly, we may use steroids along with MTX, mycophenolate, intravenous immunoglobulin (IVIg), or rituximab. Ongoing clinical trials investigating the use of tocilizumab, abatacept, and other agents offer promising potential therapies. Great strides have been made in treating skin disease in SSc. And with recent trials focusing on early SSc disease, this will allow for a greater insight into the mechanisms underlying SSc especially as it relates to skin, and the expansion of future treatment options in this field. 


\section{Introduction}

Although for many patients with diffuse systemic sclerosis (SSc), the major impact of SSc may be from involvement in the visceral organs (e.g., heart, lung, kidneys, and gut in particular); there are some diffuse SSC patients whose major involvement and morbidity lies in the skin itself. In part, this issue is related to a progressive loss of function in Activities of Daily Living (ADLs) associated with increasing skin thickness (there is a strong correlation between skin thickness as assessed by the modified Rodnan Skin thickness Score (mRSS) [1] and function as assessed by the Disability Index of the Health Assessment Questionnaire (HAQ-DI)). The loss of function is usually caused by the increasing contractures of small and large joints [2]. In addition, patients with early diffuse SSc often complain of diffuse itching, musculoskeletal (MSK) pain, and fatigue, particularly in the first few years of SSc. After the skin thickness stabilizes and then begins to improve, function may improve some and the symptoms of fatigue, body aching, and itching may also improve as the skin softens (mRSS decreases).

Needless to say, many patients with diffuse skin thickening will have concurrent problems of MSK pain, fatigue, itching, and joint contracture, and at times these symptoms may be severe enough for patients to seek treatment for these skin-related issues alone. Unfortunately, about $6-12 \%$ of SSc patients (mixed limited and diffuse SSc) will have inflammatory myositis $[3,4]$, about $40 \%$ will have progressive interstitial lung disease [5], $16 \%$ will have "synovitis" [6], and $22 \%$ will have tendon friction rubs [7] that may require immunosuppressive medical treatments themselves [8]. The treatments for these other organ involvements may influence treatment decisions for thick skin (Fig. 1).

\section{Treatments}

We have tried to present the level of evidence for the use of treatments where evidence actually exists. The levels of evidence are as follows: (A) two randomized controlles trials (RCTs) or one meta-analysis, (B) one RCT or one nonrandomized trial, and (C) expert opinion [9]. The level of evidence has influenced our recommendations in that if a treatment has level A evidence, it is preferred. If no level A evidence is available, then level B evidence is recommended. If no level A or B evidence is available, then level C expert opinion is recommended. There are modifying factors in some cases such that level $\mathrm{B}$ evidence may be recommended over a level A recommendation but that is explained in the text.

Several treatments have been shown in RCT to decrease skin thickness at a rate faster than nature would alone: methotrexate (MTX) [10, 11], cyclophosphamide (CYC) [12, 13], autologous stem cell transplant

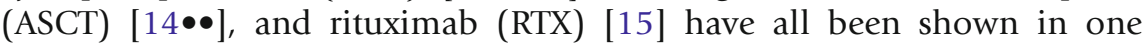
or more published RCT to significantly decrease skin thickness as measured by the mRSS. Mycophenolate mofetil (MMF) has been shown in one RCT to significantly decrease skin thickening, but this RCT has been reported in abstract only $[16,17 \bullet \bullet$. Tocilizumab (TCZ) has shown trends in decreasing skin thickness faster than a placebo in one RCT reported in two abstracts (at 24 and 48 weeks) [18, 19•]. Intravenous immunoglobulin (IV-Ig) has shown promise in case series and longitudinal series to decrease skin thickness, but its efficacy has not been proven in a RCT in SSc [20]. 


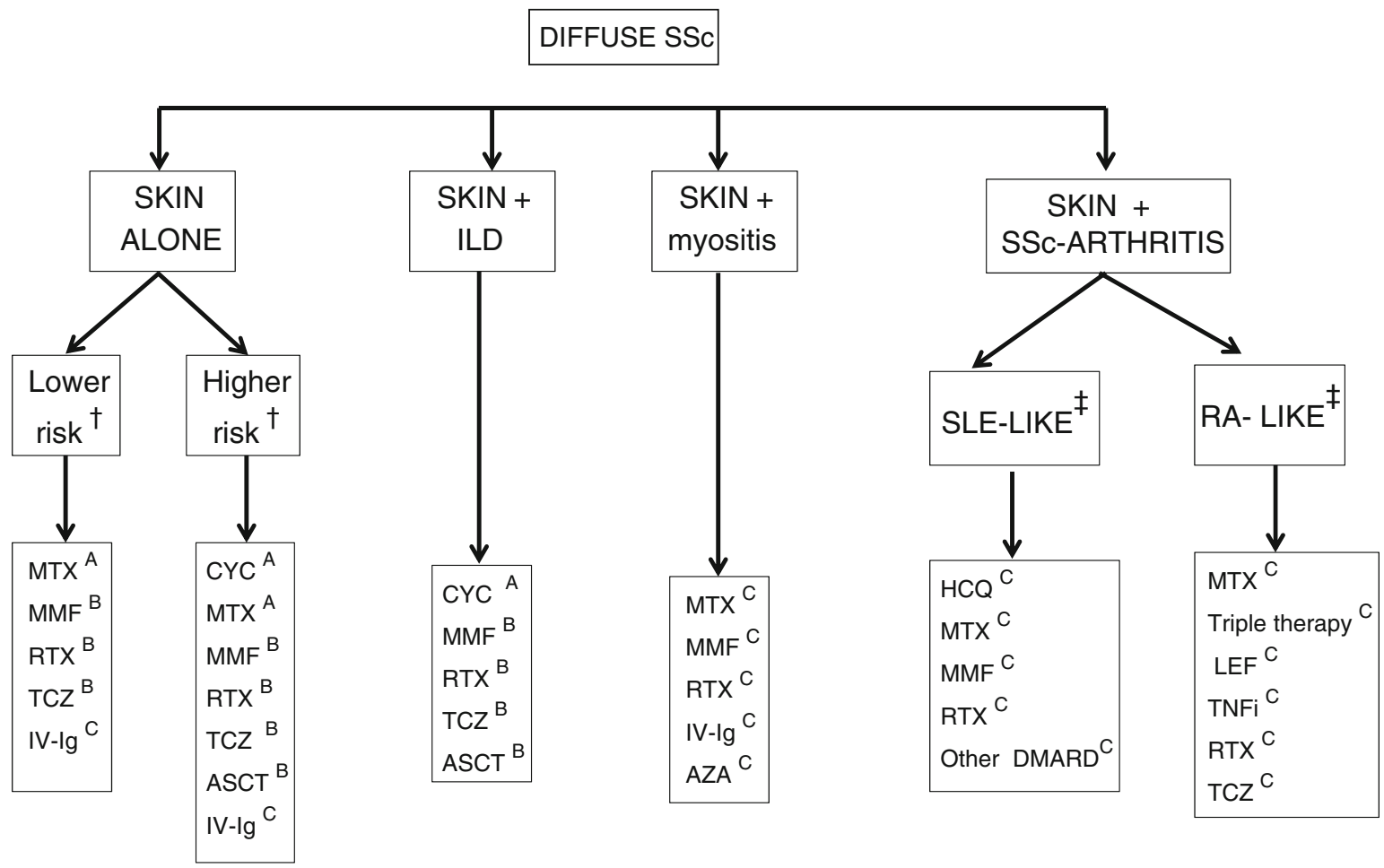

Level of evidence: ${ }^{\text {A }} 2$ RCTs or one meta-analysis; ${ }^{\mathbf{B}}$ a single RCT or nonrandomized study; ${ }^{\mathrm{C}}$ Expert opinion, case or longitudinal series. (9)

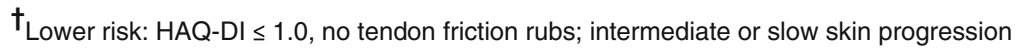

Higher risk:HAQ-DI > 1.0, very rapid or moderately rapid skin progression, tendon friction rub.

‡ SLE-like : refers to a non-erosive, non-destructive synovitis; RA- refers to an erosive destructive arthritis like RA, psoriasis or arthritis mutilans.

Fig. 1. Schema of therapeutic options for widespread skin thickening with associated organ involvements and associated level of evidence.

Although support for therapeutic options can be guided by the literature, it is important to fine tune each treatment option to the patient's current presentation. Factors such as age of the patient, male gender, child-bearing potential, rapidity with which skin thickening progresses [21], years from the onset of disease, and other organ involvements all play a role in the final treatment options. Additionally, and this may be a general rule, although support may exist for particular indication, this may not necessarily equate with an applicable mode of treatment when considering the risks and benefits of treatment options and patient's current condition. Take for instance the case of a 24-yearold female, gravida zero para zero $\left(\mathrm{G}_{0} \mathrm{P}_{0}\right)$, with the onset of disease (from the first non-Raynaud symptom) occurring 1.5 years previously, and mRSS of 10: for this patient, the physician may opt to treat with MTX as the first option (taking into account birth control issues where applicable). Additionally, MMF and RTX can serve as attractive alternative options. One could also consider the use of TCZ despite the fact 
that evidence thus far is drawn only from abstracts. IV-Ig has been studied only in an open longitudinal case series [20] with suggestively positive results for decreasing skin score.

Consider the same 24-year-old female, $\mathrm{G}_{0} \mathrm{P}_{0}$, with the same disease onset (1.5 years), with skin score of 34 that has increased by 5 units over the past 3 months and tendon friction rubs over the anterior ankles. In this case, the patient demonstrates features that suggest high-risk/poor-prognosis disease (rapidly progressive skin thickening and tendon friction rubs) [21]. A third feature that can suggest poor prognosis is a baseline HAQ-DI of $\geq 1.0$. Given the marked (and significant) progression of her skin score, the physician may opt to continue to use MTX or switch to CYC as the first options. Conversely, MMF, RTX, TCZ, IV-Ig, or ASCT may be used as alternative therapies. Keep in mind that, in both scenarios discussed, CYC could be the least favorable option in treating fertile females because of the high risk of premature ovarian failure despite RCT support. On the other hand, if the same patient were a 24-year-old male patient with what appears to have rapidly progressive skin disease (two poor prognostic signs: male and rapidly progressive skin thickening), then treatment options might include an earlier consideration of CYC or ASCT as opposed to maintaining the patient on MTX or other treatment options as discussed above.

Treating skin thickening with progressive interstitial lung disease

Several treatments have been shown to stabilize/improve the progression of

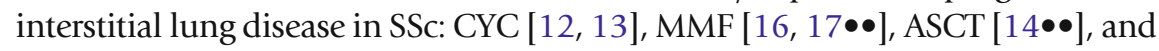
RTX [15] have been shown in at least one RCT each to significantly slow progression of, or to improve, lung physiology (specifically force vital capacity (FVC) as percent predicted) over the treatment period. TCZ has shown trends in one RCT to slow progression of, or to improve, lung physiology, but the results have been reported only in abstract form [18, 19•]. All of these treatments have also been shown in RCTs to decrease skin thickness as noted above in the previous paragraphs.

When presented with the scenario of our 24-year-old female, now presenting with an mRSS of 10 and associated decreases in FVC $(<75 \%)$ and diffusing capacity of the lungs for carbon monoxide (DLCO) $(<65 \%)$, our options may then shift to medications that potentially could treat both aspects of this patient's condition, namely the skin and lung. Hence, in considering the treatment options, we may opt to forgo CYC (for fertility reasons) but may consider the use of MMF, RTX, TCZ, or ASCT, being cautious because of potential pregnancy issues. However, in the scenario of an older, no-longer fertile female patient, or an adult male patient of any age, one may opt to consider CYC as well as those listed above. If one were to detect worsening of \%FVC and/or interstitial lung disease (ILD), for example in a 35-year-old female with an mRSS of 24 and evidence of ILD with declining FVC of $>10 \%$ (as \% predict-

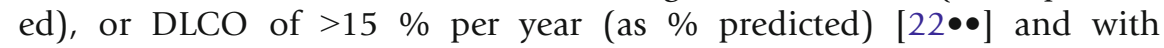
evidence of ground-glass opacities (GGO), reticulations, and honeycombing on high-resolution CT scan (HRCT), our treatment options are perhaps clearer: the use of MMF being primary (for fertility 
issues) and IV-CYC being secondary. If fertility is not an issue, then CYC or MMF would be primary and RTX and TCZ would be secondary. Consideration also may be given to ASCT, which was studied in early diffuse SSc patients who had mild to moderate heart, lung, or kidney involvements $[14 \bullet \bullet]$. The trial showed improvements in lung physiology, general ADL function, survival, and SF-36 in ASCT compared to IVCYC monthly.

Pregnancy, at any juncture in the treatment of SSc skin and ILD disease, presents a challenging treatment dilemma. Consider, for instance, a 32-year-old female with disease duration of 18 months, an mRSS of 24, and evidence of mild-moderate ILD on HRCT. To treat this patient, treatment options may be limited to the use of azathioprine (AZA) (AZA was given a "yes" during pregnancy according to the ACR recommendations while the ACR gave a "no" to TCZ, CYC, and MMF during pregnancy) [23]. Be aware, however, that the use of AZA in SScILD is limited, as it was used only in a RCT for maintenance therapy rather than induction [12].

\section{Treating thick skin with concomitant inflammatory myositis}

There are no treatments that have been shown by RCT to treat inflammatory myositis in the context of diffuse SSc. There is one published RCT that showed that intravenous immunoglobulin (IV-Ig) significantly improved the muscle disease of primary dermatomyositis [24].

Let us evaluate the case of a 34-year-old female, $\mathrm{G}_{0} \mathrm{P}_{0}$, with an 11-month history of SSc, who presents with diffuse swelling of the hands, fore/upper arms, thighs, and feet with associated difficulty rising from a chair. Her complete evaluation showed elevated creatine kinase and "irritable myopathy" on EMG, and biopsy was consistent with inflammatory myositis. Serologic evaluation showed that her RNA polymerase was negative. Her symptoms have been worsening for the past 3 months. Despite the paucity of data supporting the use of immunosuppressive therapy in SSc-associated myositis, one may opt not to use prednisone for fear of initiating renal crisis in a patient with diffuse SSc and opt instead to use IV-Ig as a stand-alone therapy. Alternatively, one may consider (although reluctantly) to use corticosteroids along with MTX, IV-Ig, MMF, RTX, or AZA.

\section{Treating skin thickening in patients who have SSc-related arthritis}

Seronegative arthritis in the context of SSc has not been well studied, and there are no RCT data to show that any treatments are effective for SSc-related arthritis $[25 \bullet, 26 \bullet]$. Those SSc patients who also have seropositive (anti-CCP) RA, however, should be treated as if they had RA alone.

Take for example a case of a 35-year-old active avid surfer female with an overlap syndrome of RA (RF+, CCP+) and SSc with an mRSS of 10 and stable FVC and DLCO near normal. Given the features presented in this scenario, one may lean towards treating the arthritis initially and not so much skin, with MTX alone or combined with triple therapy, LEF, or TNF-i. Alternatively, RTX or TCZ may be attractive treatment options. If, on the other hand, this same 35-year-old female with seropositive RA had diffuse SSc with a mRSS of 24, then MTX, RTX, and 
TCZ might treat both diffuse skin thickening and polyarthritis.

If we were to consider a situation where a patient with SSc has features of inflammatory seronegative arthritis, we may favor the use of DMARDs (including MTX, HCQ, sulfasalazine, and/or leflunomide (LEF)) or a combination of the aforementioned treatments. Moreover, if we were to consider a 68-year-old female with overlap syndrome with features of SSc with limited cutaneous scleroderma and seronegative polyarthritis with evidence of ILD on exam, our treatment options may shift to a course that better addresses ILD rather than isolated polyarthritis, such as CYC, MMF, ASCT, and TCZ.

\section{Treating SSc skin disease in the setting of severe GI symptoms}

GI symptoms including severe GERD, difficulty swallowing, gastric dysmotility, bacterial overgrowth, and malabsorption (among others) are present in up to $80 \%$ of SSc patients and often contribute to increased morbidity and mortality [27]. Although the majority of GI involvements are treated symptomatically, at times and if severe, these symptoms often may present a hurdle in treating skin disease. Therapeutic options that bypass the GI system may then present as more viable options in treating SSc skin disease.

For example, a 45-year-old female with a 3-year history of diffuse SSc and inflammatory synovitis (seronegative) presents for an evaluation regarding her persistent skin thickness. She has a number of hospitalizations related to decreased motility, abnormal bowel habits with alternating diarrhea and constipation, and symptoms/signs of malabsorption/pseudo-obstruction. Her examination reveals a skin score of 15 . She is particularly concerned about the use of her hands, as they feel swollen and painful. Given the predominance of GI symptoms in this patient, oral therapies may be of limited use. The physician may consider parenteral MTX [28], TCZ, RTX, IV-Ig, or CYC. If she were also to have progressive ILD, the physician could consider using IV-CYC initially and consider RTX or TCZ secondarily.

\section{Therapeutic agents: evidence of efficacy (see Table 1)}

\section{Methotrexate}

MTX was studied in two RCTs $[10,11]$ that showed statistically significant efficacy in decreasing skin thickness (using mRSS) in SSc. There are no RCTs that have evaluated MTX in treating myositis or arthritis in SSc although expert opinion suggests that MTX may be efficacious in treating myositis and arthritis in SSc. Caution should be exercised when switching MTX treatment routes: Because the subcutaneous form of MTX is more readily bioavailable, a 25-mg subcutaneous dose may be equivalent to $30 \mathrm{mg}$ orally [28].

CYC has been studied in three RCTs $[12,13,16,17 \bullet \bullet]$ that showed significant efficacy of CYC in halting/improving the progression of SScILD: two were published and one has been reported in abstract form 


\begin{tabular}{|c|c|c|c|c|}
\hline Medication & Abbreviations & Route & Dose & $\begin{array}{l}\text { Dose modifications for renal } \\
\text { disease* }\end{array}$ \\
\hline Methotrexate & MTX & $\mathrm{PO} / \mathrm{SC}$ & $\begin{array}{l}\text { PO: Starting dose variable, } \\
7.5-15 \mathrm{mg} \text {; may be increased } \\
\text { to } 25 \mathrm{mg} \text { weekly. } \\
\text { SC: } 25 \mathrm{mg} \mathrm{SC} \text { may be equal to } \\
30 \mathrm{mg} \text { PO [28] }\end{array}$ & $\begin{array}{l}\mathrm{Cr} \text { Cl10-50: decrease dose by } \\
50 \% ; \mathrm{CrCl}<10 \text { : avoid use }\end{array}$ \\
\hline Cyclophosphamide & $\mathrm{CYC}$ & IV/PO & $\begin{array}{l}\text { IV: Graduated dose } \\
500-750 \mathrm{mg} / \mathrm{m}^{2} \text { (per SCOT } \\
\text { Trial Protocol) or } 600 \mathrm{mg} / \mathrm{m}^{2} \\
\text { (per FAST trial) } \\
\text { PO: } 1-2 \mathrm{mg} / \mathrm{kg} / \text { day }\end{array}$ & $\mathrm{Cr} \mathrm{Cl}<10$ : decrease dose by $25 \%$ \\
\hline $\begin{array}{l}\text { Mycophenolate } \\
\text { mofetil }\end{array}$ & MMF & $\mathrm{PO}$ & $\begin{array}{l}\text { Up to } 1.5 \mathrm{~g} \text { BID of MMF. } \\
\text { Alternatively, mycophenolic } \\
\text { acid up to } 1080 \mathrm{mg} \text { BID }\end{array}$ & $\begin{array}{l}\mathrm{Cr} \mathrm{Cl}<25 \text { : consider decreasing } \\
\text { dose to } 1 \mathrm{~g} \text { BID. HD/PD not } \\
\text { well defined }\end{array}$ \\
\hline Rituximab & RTX & IV & $\begin{array}{l}1000 \text { mg two doses } 2 \text { weeks } \\
\text { apart. May repeat every } \\
6 \text { months. }\end{array}$ & Renal dosing not defined \\
\hline Tocilizumab & TCZ & $\begin{array}{l}\text { SC } \\
\text { IV }\end{array}$ & $\begin{array}{l}\text { SC: } 162 \mathrm{mg}, 2 \text { weeks } \\
\text { IV: } 4-8 \mathrm{mg} / \mathrm{kg} \text { monthly }\end{array}$ & $\begin{array}{l}\mathrm{Cr} \text { Cl 50-80: no adjustment; } \mathrm{Cr} C l \\
\quad<50 \text { and HD: not defined }\end{array}$ \\
\hline $\begin{array}{l}\text { Intravenous } \\
\text { immune globulin }\end{array}$ & IV-Ig & IV & $\begin{array}{l}\text { The recommended dose of } \\
\text { IV-Ig is } 2 \mathrm{~g} / \mathrm{kg} \text { divided over } \\
2-4 \text { days, repeated every } 3-4 \\
\text { weeks }\end{array}$ & Not defined \\
\hline Azathioprine & AZA & PO & $1.5-2 \mathrm{mg} / \mathrm{kg}$ daily & $\begin{array}{l}\mathrm{Cr} \mathrm{Cl} 10-50 \text { : decrease by } 25 \% ; \mathrm{Cr} \\
\mathrm{Cl}<10 \text { : decrease dose by } 50 \% \text {; } \\
\text { HD: } 0.25 \mathrm{mg} / \mathrm{kg} ; \text { PD not } \\
\text { defined }\end{array}$ \\
\hline Hydroxychloroquine & $\mathrm{HCQ}$ & PO & $\begin{array}{l}200-400 \mathrm{mg} \text { daily (not to } \\
\text { exceed } 6.5 \mathrm{mg} / \mathrm{kg} \text { total daily } \\
\text { dose) }\end{array}$ & Not defined \\
\hline Leflunomide & LEF & PO & $10-20 \mathrm{mg}$ daily & No adjustment \\
\hline
\end{tabular}

only. Two of the above RCTs also showed that CYC was significantly efficacious in decreasing the skin thickness of diffuse SSc [13, 16, 17••]. Although oral CYC was used in several of the RCTs noted above, evidence elsewhere suggests that CYC can be given intravenously, in large part to reduce cumulative dose (for example, the cumulative annual dose IV may be $12 \mathrm{~g}$ whereas the annual oral dose may be $36 \mathrm{~g}$ ). Additionally, the IV form of CYC as prescribed in rheumatic diseases is associated with a lower risk of cystitis, and in turn, a lower risk of bladder cancer [29].

MMF has been studied in one RCT $[16,17 \bullet \bullet]$ that showed significant efficacy of MMF in decreasing skin thickness and halting/improving the progression of SSc-ILD. There are no RCTs that have evaluated 
MMF in treating myositis or arthritis in SSc although expert opinion suggests that MMF may be efficacious in treating the myositis and arthritis of SSc.

\section{Rituximab}

RTX has been studied in one RCT [15] that showed significant efficacy of RTX in decreasing skin thickness and halting/improving the progression of SSc-ILD. There are no RCTs that have evaluated RTX in treating myositis or arthritis although expert opinion suggests that RTX may be efficacious in treating myositis and arthritis of SSc.

\section{Tocilizumab}

TCZ has been studied in one RCT $[18,19 \bullet]$ that showed trends for efficacy in decreasing skin thickness and halting/improving the progression of SSc-ILD (reported in abstract form at 24 and at 48 weeks).

\section{Intravenous immunoglobulin}

IV-Ig has been studied in one RCT [24] that showed significant efficacy in improving strength in inflammatory dermatomyositis. In an open longitudinal study, IV-Ig use was associated with a decrease in skin fibrosis (using the mRSS) [20]. There are no RCTs that have evaluated IV-Ig in treating skin thickness, arthritis, or myositis of SSc or halting/slowing the progression of ILD in SSc although expert opinion suggests that IV-Ig may be efficacious in treating myositis and arthritis of SSc.

\section{Autologous stem cell transplantation}

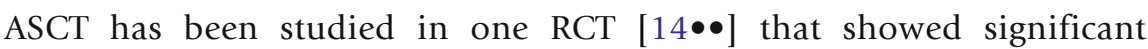
efficacy in decreasing skin thickness, halting/slowing the progression of ILD, improving function (HAQ-DI), and improving the physical component of the SF-36.

\section{Other treatments}

There are no RCTs that have evaluated TNF-inhibitors, hydroxychloroquine, leflunomide, or azathioprine in treating skin thickening, myositis, or arthritis of SSc. Expert opinion suggests that one or more of the aforementioned treatments may be efficacious in treating skin thickness, myositis, or arthritis in SSc. Of note, Hoyles et al. reported on the use of AZA in the setting of maintenance rather than induction therapy in one RCT in the setting of ILD in SSc [12]. Its place in the SSc therapeutic armament in general has not been adequately defined.

\section{Choosing treatment options}

When choosing treatments, consideration should be given to poor prognostic indicators such as tender friction rubs, male gender, African American race, and rapidly progressive skin changes in addition to concomitant organ involvement as discussed above. The presence of one or more of these prognostic indicators suggests that SSc will have 
a more aggressive course and may require a more aggressive therapeutic approach. It is important to bear in mind that despite the fact that some treatments are supported by randomized controlled trials, clinical experience and trends for improvement or worsening may be important in the day-to-day treatment of patients with scleroderma. Tailoring treatment options to each patient's specific needs may involve several different regimens. The options provided above are meant to guide the practicing rheumatologist in treating skin thickening in SSc patients. Variability in the choice of treatment may also be guided by the experiences and comfort of the rheumatologist with each treatment regimen.

\section{Duration of treatment}

As a rule of thumb, in our practice, any treatment modality chosen is carried out for at least 6 months. During this time, trends for improvement or lack thereof are followed closely and further critical treatment decisions are made. Treatment for diffuse skin thickening is often continued until skin thickening has decreased sufficiently (often when the mRSS has declined to 6-10 units). On the other hand, if skin thickness is not improving by 6-12 months, an alternative treatment option can be considered. When it comes to treating synovitis (tender and/or swollen joints), long-term treatment plans are quite the norm. In the meantime, switching treatment options can be considered if synovitis is not improved following 3-6 months of treatment. When interstitial lung disease and skin thickening are concurrent concerns, we obtain PFTs at 3-month intervals to determine trends in \%FVC and $\%$ DLCO. Since it is important to keep in mind that declines of $\geq 10 \%$ in FVC and/or $\geq 15 \%$ in DLCO over 6-12 months are predictors of further losses of lung function, any such declines should warrant treatment reassessment. The treatment for myositis is also generally long term, and switching modes of treatment could be considered on a case by case basis. Overall, the treating physician may choose to change treatment following 6 months of treatment.

\section{Future direction}

Skin involvement in SSc continues to be a palpable therapeutic challenge to the treating rheumatologist. To date, no specific treatment has been shown to be single-handedly effective in treating skin fibrosis. Clinical trials investigating the role of potential treatments in SSc skin are ongoing. In fact, a review of http://clinicaltrials.gov/ reveals a number of RCT where the primary or secondary focus is to evaluate the effect of a number of treatments on skin thickening in SSc. Such investigations involving the use of IV-Ig, MMF, TCZ, bortezomib, belimumab, rituximab, abatacept, TCZ, and ACST are underway. Current research continues to target a number of aspects and potential pathways that may be involved in SSc: inflammatory, pro-fibrotic, signal transduction, 
and transcription factors for example. Great strides have been made in the evaluation and treatment of SSc skin disease, and we are hopeful for identifying effective therapeutic options.

\section{Compliance with Ethical Standards}

Funding

This work was supported by grants from the NHLBI/NIH: R01 HL089758 and R01 HL089901.

\section{Conflict of Interest}

Suzanne Kafaja declares that she has no conflict of interest. Philip Clements declares that he has no conflict of interest.

Human and Animal Rights and Informed Consent

This article does not contain any studies with human or animal subjects performed by the authors.

\section{References}

Papers of particular interest, published recently, have been highlighted as:

- Of importance

- Of major importance

1. Clements PJ, Hurwitz EL, Wong WK, Seibold JR, Mayes $\mathrm{M}$, White B, et al. Skin thickness score as a predictor and correlate of outcome in systemic sclerosis: high-dose versus low-dose penicillamine trial. Arthritis Rheum. 2000;43(11):2445-54.

2. Clements PJ, Wong WK, Hurwitz EL, Furst DE, Mayes $\mathrm{M}$, White $\mathrm{B}$, et al. The Disability Index of the Health Assessment Questionnaire is a predictor and correlate of outcome in the high-dose versus low-dose penicillamine in systemic sclerosis trial. Arthritis Rheum. 2001;44(3):653-61.

3. Bhansing KJ, Lammens M, Knaapen HK, van Riel PL, van Engelen BG, Vonk MC. Scleroderma-polymyositis overlap syndrome versus idiopathic polymyositis and systemic sclerosis: a descriptive study on clinical features and myopathology. Arthritis Res Ther. 2014;16(3):R111.

4. Balbir-Gurman A, Braun-Moscovici Y. Scleroderma overlap syndrome. Isr Med Assoc J. 2011;13(1):14-20.

5. Steen VD, Conte C, Owens GR, Medsger Jr TA. Severe restrictive lung disease in systemic sclerosis. Arthritis Rheum. 1994;37(9):1283-9.

6. Avouac J, Walker U, Tyndall A, et al. Characteristics of joint involvement and relationships with systemic inflammation in systemic sclerosis: results from the EULAR Scleroderma Trial and
Research Group (EUSTAR) database. J Rheumatol. 2010;37:1488-501.

7. Khanna PP, Furst DE, Clements PJ, Maranian P, Indulkar L, Khanna D, et al. Tendon friction rubs in early diffuse systemic sclerosis: prevalence, characteristics and longitudinal changes in a randomized controlled trial. Rheumatology (Oxford). 2010;49(5):955-9.

8. Muangchan C, Baron M, Pope J, Canadian Scleroderma Research Group. The 15\% rule in scleroderma: the frequency of severe organ complications in systemic sclerosis. A systematic review. J Rheumatol. 2013;40(9):1545-56.

9. Grossman JM, Gordon R, Ranganath VK, Deal C, Caplan L, Chen W, et al. American College of Rheumatology 2010 recommendations for the prevention and treatment of glucocorticoidinduced osteoporosis. Arthritis Care Res (Hoboken). 2010;62:1515-26.

10. Van den Hoogen FH, Boerbooms AM, Swaak AJ, Rasker JJ, van Lier HJ, van de Putte LB. Comparison of methotrexate with placebo in the treatment of systemic sclerosis: a 24 week randomized double-blind trial, followed by a 24 week observational trial. Br J Rheumatol. 1996;35(4):364-72. 
11. Pope JE, Bellamy N, Seibold JR, Baron M, Ellman M, Carette $\mathrm{S}$, et al. A randomized, controlled trial of methotrexate versus placebo in early diffuse scleroderma. Arthritis Rheum. 2001;44(6):1351-8.

12. Hoyles RK, Ellis RW, Wellsbury J, Lees B, Newlands P, Goh NS, et al. A multicenter, prospective, randomized, double-blind, placebo-controlled trial of corticosteroids and intravenous cyclophosphamide followed by oral azathioprine for the treatment of pulmonary fibrosis in scleroderma. Arthritis Rheum. 2006;54(12):3962-70.

13. Tashkin DP, Elashoff R, Clements PJ, Goldin J, Roth $\mathrm{MD}$, Furst DE, et al. Cyclophosphamide versus placebo in scleroderma lung disease. $\mathrm{N}$ Engl J Med. 2006;354(25):2655-66.

14.• Van Laar JM, Farge D, Sont JK, Naraghi K, Marjanovic Z, Larghero J, et al. Autologous hematopoietic stem cell transplantation vs intravenous pulse cyclophosphamide in diffuse cutaneous systemic sclerosis: a randomized clinical trial. JAMA. 2014;311(24):2490-8.

The ASTIS trial is the first randomized controlled trial of autologous stem cell transplantation versus monthly intravenous cyclophosphamide for 12 months in the treatment of early diffuse SSc. The results showed statistically significant improvements in decreasing skin thickness, halting/slowing the progression of ILD, improving function (DHAQ-DI), and improving the physical component of the SF-36 in the subjects who received autologous stem cell transplantation compared to subjects who received cyclophosphamide.

15. Daoussis D, Liossis SN, Tsamandas AC,

Kalogeropoulou C, Kazantzi A, Sirinian C, et al. Experience with rituximab in scleroderma: results from a 1year, proof-of-principle study. Rheumatology (Oxford). 2010;49(2):271-80.

16. Clements PJ, Tashkin D, Roth M, Khanna D, Furst DE Tseng CH, et al. The Scleroderma Lung Study II (SLS II) shows that both oral cyclophosphamide (CYC) and mycophenolate Mofitil (MMF) are efficacious in treating progressive interstitial lung disease (ILD) in patients with systemic cclerosis (SSc). Abstract, 2015 ACR Annual Meeting, San Francisco, CA. oral presentation. 1075

17.• Tashkin D, Roth M, Clements P, Furst D, Khanna D, Goldin J, et al. Efficacy and safety of mycophenolate (MMF) vs oral cyclophosphamide (CYC) for treatment of scleroderma-interstitial lung disease (SSc-ILD): results of Scleroderma Lung Study II. Chest J Chest. 2015, Vol 148, Meeting abstracts 2015).

Scleroderma Lung Study II showed that 2 years of oral mycophenolate mofitil (MMF) stabilized or improved lung physiology, decreased dyspnea and decreased thickened / indurated skin in early SSc to the same degree as one year of oral cyclophosphamide (CYC). MMF was also better tolerated than CYC while the only significant difference in adverse effect profile lay in thrombocytopenia that was seen predominantly in CYC patients.
18. Khanna D, Denton C, Van Laar JM, Jahreis A, Cheng S, Spotswood H, et al. Safety and efficacy of subcutaneous tocilizumab in adults with systemic sclerosis: week 24 data from a phase $2 / 3$ trial. Abstract, Meeting: 2014 ACR/ARHP Annual Meeting. 2014

19.• Khanna D, Denton CP, Jahreis A, Van Laar JM, Cheng S, Spotswood H, et al. Safety and efficacy of subcutaneous tocilizumab in adults with systemic sclerosis: week 48 data from the FASSCINATE Trial. Abstract, EULAR 2015 .

The use of subcutaneous tocilizumab (TCZ) was tested in a double-blind, randomized placebo-controlled trial in diffuse SSc. The results showed strong trends for improvement in cutaneous induration and lung physiology in the TCZ arm compared to the placebo arm in this 48-week trial.

20. Levy Y, Amital H, Langevitz P, Nacci F, Righi A, Conforti L, et al. Intravenous immunoglobulin modulates cutaneous involvement and reduces skin fibrosis in systemic sclerosis: an open-label study. Arthritis Rheum. 2004;50(3):1005-7. No abstract available.

21. Domsic RT, Rodriguez-Reyna T, Lucas M, Fertig N, Medsger Jr TA. Skin thickness progression rate: a predictor of mortality and early internal organ involvement in diffuse scleroderma. Ann Rheum Dis. 2011;70(1):104-9.

22.• Moore OA, Proudman SM, Goh N, Corte TJ, Rouse H, Hennessy $\mathrm{O}$, et al. Quantifying change in pulmonary function as a prognostic marker in systemic sclerosisrelated interstitial lung disease. Clin Exp Rheumatol. 2015;33(4 Suppl 91):S111-6.

In this study, it was shown that declines in \%forced vital capacity $\geq 10 \%$ or in \%diffusing capacity for carbon monoxide $\geq 15 \%$ over 1 year of follow-up were predictive of progressive interstitial lung disease in SSc.

23. Ruiz-Irastorza G, Khamashta M, Dalakas MC, Illa I, Dambrosia JM, Soueidan SA, et al. Pregnancy and rheumatic disease. ACR website 2014. A controlled trial of high-dose intravenous immune globulin infusions as treatment for dermatomyositis. N Engl J Med. 1993;329(27):1993-2000.

24. Dalakas MC, Illa I, Dambrosia JM, Soueidan SA, Stein DP, Otero C, et al. A controlled trial of high-dose intravenous immune globulin infusions as treatment for dermatomyositis. N Engl J Med. 1993;329(27):1993-2000.

25. Walker KM, Pope J. Participating members of the Scleroderma Clinical Trials Consortium (SCTC), Canadian Scleroderma Research Group. Treatment of systemic sclerosis complications: what to use when first-line treatment fails-a consensus of systemic sclerosis experts. Semin Arthritis Rheum. 2012;42:42-55.

This was not a scientific study of the practices of scleroderma experts from around the world. Rather, it was the questioning of physicians of what the physicians themselves thought about how they treated polyarthritis and other musculoskeletal manifestations as they occur in systemic sclerosis. 
26. Clements PJ, Allanore Y, Khanna D, Singh M, Furst DE. Arthritis in systemic sclerosis: systematic review of the literature and suggestions for the performance of future clinical trials in systemic sclerosis arthritis. Semin Arthritis Rheum. 2012;41:801-14.

This systematic literature review revealed that there was very little in the way of systematically performed studies of outcomes or of therapies that could impact polyarthritis or other musculoskeletal manifestation of systemic sclerosis.

27. Baron M, Bernier P, Cote F, DeLegge MH, Falovitch G, Friedman $G$, et al. Screening and management of malnutrition and related gastro-intestinal disorders in systemic sclerosis: recommendations of a North American expert panel. Clin Exp Rheumatol. 2010;28 Suppl 58:S42-6.

28. Hamilton RA, Kremer JM. Why intramuscular methotrexate may be more efficacious than oral dosing in patients with rheumatoid arthritis. Br J Rheumatol. 1997;36(1):86-90.

29. Monach PA, Arnold LM, Merkel PA. Incidence and prevention of bladder toxicity from cyclophosphamide in the treatment of rheumatic diseases: a data-driven review. Arthritis Rheum. 2010;62(1):9-21. 